\title{
Novel Coronavirus: A Newly Arranged Mini-Review
}

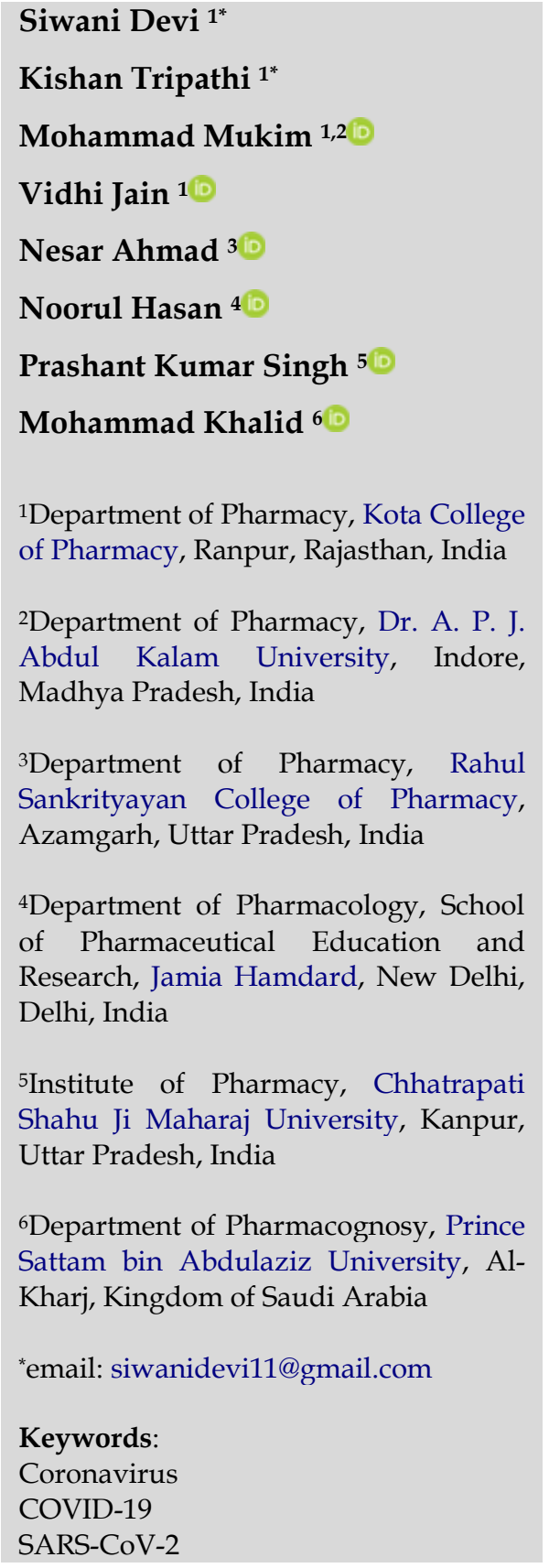

\begin{abstract}
Severe acute respiratory syndrome coronavirus 2 (SARS-CoV-2), which was originally known as a virus that infects animals and rarely can be transmitted to humans in large populations, is now transformed into one of the most feared pandemics causes worldwide. Infection by a virus that is officially known as COVID-19 has caused global concern mainly due to the number of deaths caused. Since it was first reported in Wuhan, China in December 2019, now COVID19 has spread to almost all parts of the world with a very rapid spread rate. The main symptom of this infection is a respiratory disease accompanied by other symptoms that resemble flu-like illness. Everyone can suffer from COVID-19, but the elderly, toddlers, pregnant women, and people with certain diseases and disorders of the immune system show more severe symptoms. The disease is transmitted through inhalation or contact with droplets, where the incubation period ranges from 2 to 14 days. Until now, specific therapy to treat COVID-19 has not been found, with preventive measures taken to control its spread. In this mini-review, we will explain important information related to COVID-19.
\end{abstract}

Received: May 29th, 2020

Accepted: June 17th, 2020

Published: June 22nd, 2020

(c) 2020 Siwani Devi, Kishan Tripathi, Mohammad Mukim, Vidhi Jain, Nesar Ahmad, Noorul Hasan, Prashant Kumar Singh, Mohammad Khalid. Published by Institute for Research and Community Services Universitas Muhammadiyah Palangkaraya. This is an Open Access article under the CC-BY-SA License (http://creativecommons.org/licenses/by-sa/4.0/). DOI: https://doi.org/10.33084/bjop.v3iSpecial-1.1428

\section{INTRODUCTION}

Coronavirus is a spherical or pleomorphic enveloped particulate containing a single-stranded [positive sense] RNA associated with a capsid nucleoprotein consisting of a matric protein. The envelope carries a club-shaped glycoprotein projection. It belongs to the Phylum Pisuviricota, the Nidovirales order, the Coronaviridae family, and the Betacoronavirinae genera (Pal et al., 2020). 
Their viral RNA genome is 26 to 32 kilobases in length. It is a highly diffuse virus spread by droplets, direct contact, and contact with infected objects (Chen et al., 2020). Coronavirus is a large family of viruses that can infect birds and mammals, including humans, according to the World Health Organization. The virus is responsible for causing severe acute respiratory syndrome (SARS) (Raoult et al., 2020; Woo et al., 2010).

On January $24^{\text {th }}, 2020$, at least 830 cases were diagnosed in nine countries: China, Thailand, Japan, South Korea, Singapore, Nepal, Vietnam, and Taiwan (Tan et al., 2020). And by the end of December 2019, a virus from a similar family group had re-emerged in Wuhan and had even become a global pandemic (Mackenzie \& Smith, 2020). The virus was officially named 2019 novel coronavirus (2019-nCoV) and is also known as SARS-CoV-2 (Wang et al., 2020). Therapies that have proven to be particularly effective in the treatment of SARS-CoV-2 infection, known as coronavirus disease 2019 (COVID-19), have not yet been identified and are still being extensively studied by scientists around the world (Yi et al., 2020). In this mini-review, we will discuss all kinds of ins and outs related to SARS-CoV-2 along with the COVID-19 outbreak that threatens all human beings in the world, starting with the classification and transmission of SARSCoV-2, diagnosis, symptoms, management, and prevention of COVID-19. The whole discussion will be presented with a new perspective, with actual and relevant references.

\section{CORONAVIRUS CLASSIFICATION}

The classification of SARS-CoV-2 is shown in Figure 1. In general, SARS-CoV-2 has the same beta coronavirus genera as SARS-CoV which causes SARS and MERS$\mathrm{CoV}$ which causes MERS. However, the lineage/strain difference causes SARS-CoV-2 to show more pathogenicity than both (Pal et al, 2020). Besides, there are also several species of coronavirus that specifically infect humans, including Human coronavirus 229E (HCoV229E), Human coronavirus NL63 (HCoV-NL63), Human coronavirus OC43 (HCoV-OC43), and Human coronavirus HKU1 (HCoV-N43) (Liu et al., 2020).

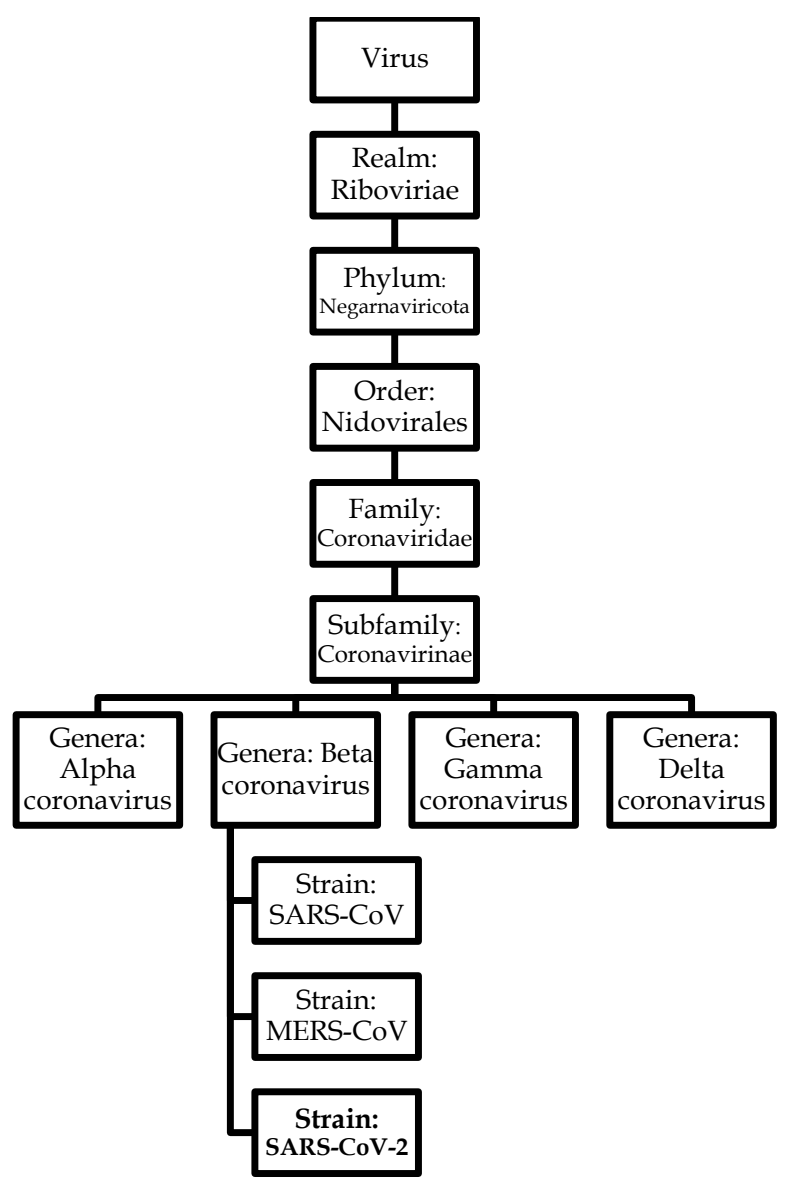

Figure 1. Classification and origins of SARS-CoV-2 (Pal et al., 2020)

\section{COVID-19 TRANSMISSION}

COVID-19 is transmitted through droplets from the physiological fluids of infected individuals and can be transmitted with various droplet sizes when the droplet particle size is $>5-10 \mu \mathrm{m}$, the other droplets are transmitted through the respiratory tract, and when the droplet particles are $<5 \mu \mathrm{m}$ in diameter, they are referred to as the core droplets (Atkinson et al., 2009). According to current evidence, COVID-19 is mainly transmitted between people via respiratory droplets and direct contact routes. Droplet transmission occurs when a 
person is in close contact with a radius of $1 \mathrm{~m}$ with someone who has symptoms of respiratory distress, where the individual is at risk of inhaling droplets and is exposed to oral/nasal mucosa or eye conjunctiva and is also exposed to SARS-CoV-2 (Wilson et al., 2020). Transmission can also occur through fomites in the immediate vicinity of infected people (Huang et al., 2020). Some types of coronavirus that infect animals such as cat coronavirus (FeCoV) may spread through contact with the face. However, it is not clear whether this also applies to humans (Weiss \& Navas-Martin, 2005).

\section{COVID-19 DIAGNOSIS}

The U.S. CDC has developed criteria for persons under investigation (PUIs). If a person is considered to be a PUI, immediate prevention, infection, and control measures shall be taken. Epidemiological factors are used to assess the test requirement. These include close contact with a laboratory-confirmed patient with 14 days of symptoms or a history of travel to the infected area within 14 days of onset on symptoms (Ghinai et al., 2020; Yin \& Wunderink, 2018).

Chest X-rays (CXRs) usually show bilateral infiltration but may be normal in early illness. Computed Tomography (CT) is more sensitive and more specific. The CT imagery generally shows infiltrates, ground opacities, and sub-segmental consolidation. It is also abnormal in asymptomatic patients who have no clinical evidence of lower respiratory tract involvement. Abnormal CT scans were used to diagnose COVID-19 in suspected cases with a negative molecular diagnosis; many of these patients had positive re-test molecular tests (Cascella et al., 2020).

\section{COVID-19 SYMPTOMS}

In general, the signs and symptoms are shown in people suffering from COVID-19 almost resemble the symptoms that are shown in cases of other viral infections such as fever, dry cough, and muscle aches (Singhal, 2020). Therefore, people often do not realize that they are infected with COVID-19 because they feel that they have other diseases. Some patients show no clinical symptoms at all (Raoult et al., 2020; Cascella et al., 2020). However, of the majority of cases that occur, it is reported that people who are infected show symptoms of flu-like illness, such as:

Most common

1. Fever

2. Dry cough

3. Tiredness

Less common

1. Muscle aches

2. Sore throat

3. Diarrhea

4. Conjunctivitis

5. Headache

6. Loss of taste or smell

7. Rash on skin

From these symptoms, some people show severe symptoms and require immediate medical attention, including:

1. Shortness of breath

2. Chest pain

3. Difficulty in communication

It takes 5-6 days, on average, to have symptoms from someone infected by the virus, but it may take up to 14 days (World Health Organization, 2020a).

\section{COVID-19 MANAGEMENT}

As of the end of May 2020 at the time this article was written, effective treatments to cure COVID-19 infections have not yet been found. Various pharmaceutical companies and research groups are still developing vaccines and repurposing drug compounds to find the 
most effective and optimal treatment for COVID-19 (Amawi et al., 2020; Savi et al., 2020; Wu et al., 2020). The management of COVID-19 patients is prioritized based on the condition of each patient, where patients who have only mild symptoms or no symptoms at all are recommended to improve the body's immune system and treat the mild symptoms that arise (Ali \& Alharbi, 2020). While in patients with medium and severe conditions, also given supportive therapy such as administration of antipyretic and analgesic, maintenance of hydration, and administration of oxygen. Medical therapy involving corticosteroids and antivirals has also been encouraged as part of critical management schemes. However, there is currently no specific antiviral recommended for the treatment of COVID-19 (Nicola et al., 2020). In patients with COVID-19 with severe conditions and experiencing acute respiratory distress syndrome (ARDS), the use of a ventilator as a respiratory aid is mandatory and crucial. However, not all health facility units have sufficient ventilators, while ventilators that are used incorrectly can increase the patient's mortality rate (Iyengar et al., 2020; Möhlenkamp \& Thiele, 2020).

\section{COVID-19 PREVENTION}

In addition to using masks and face shields, prevention of transmission of COVID-19 is done by maintaining a safe distance between people to avoid direct contact with droplets that may contain viruses (Perencevich et al., 2020). Washing your hands as often as possible using soap and running water is also mandatory, and if not available, it can be replaced with alcohol-based hand sanitizers. Equally important is avoiding traveling to a place where it is crowded with people (Jayaweera et al., 2020). Some ways to prevent the spread of COVID-19 as summarized by the World Health Organization (2020b) include:
1. Clean your hands up often. Use soap and water, or rub a hand based on alcohol.

2. Keep a safe distance from anyone who's coughing or sneezing.

3. Don't touch your eyes, your nose, or your mouth.

4. If you cough or sneeze, cover your nose and mouth with your bent elbow or tissue.

5. Stay at home if you feel uneasy.

6. If you have fever, cough, or difficulty breathing, seek medical attention. Please call in advance.

7. Follow the instructions of your local health authority.

\section{CONCLUSION}

Findings show that large portions of the study participant are aware and knowledgeable about COVID-19 and its presence in Nigeria. Results obtained from the research questions regarding knowledge of COVID-19 in terms of respondents' knowledge of the source, transmission, symptoms, preventive behavior, the fatality rate of the COVID-19, and the major resources of information about COVID-19 among north-central Nigerians were significantly high. A large portion of the study participant is scared of the COVID-19 pandemic and its outbreak in Nigeria this may be a result of the high rate of a fatality caused by this pandemic worldwide. This could imply that the respondents apprehend about COVID-19. The knowledge on COVID-19 could, therefore, support a better capacity to adopt precautionary measures leading to the control of the disease as was in the case of ebola.

\section{REFERENCES}

Ali, I. \& Alharbi, O.M.L. (2020). COVID-19: Disease, management, treatment, and social impact. Science of the Total Environment, 728, 138861. doi:10.1016/j.scitotenv.2020.138861

Amawi, H., Deiab, GA., Aljabali, A.A.A., Dua, K., \& Tambuwala, M.M. (2020). COVID-19 pandemic: an overview of epidemiology, 
parthenogenesis, diagnostics and potential vaccines and therapeutics. Therapeutic Delivery, [Epub ahead of print]. doi:10.4155/tde-20200035

Atkinson, J., Chartier, Y., \& Pessoa-Silva, C.L. (2009). Natural Ventilation for Infection Control in HealthCare Settings. Geneva, Swiss: World Health Organization

Cascella, M., Rajnik, M., Cuomo, A., Dulebohn, S.C., \& Di Napoli, R. (2020). Features, Evaluation and Treatment Coronavirus (COVID-19). In: StatPearls. Treasure Island, Florida: StatPearls Publishing.

Chen, B., Tian, E.K., He, B., Tian, L., Han, R., Wang, S., Xiang, Q., Zhang, S., El Arnaout, T., \& Cheng, W. (2020). Overview of lethal human coronaviruses. Signal Transduction and Targeted Therapy, 5, 89. doi:10.1038/s41392-020-0190-2

Ghinai, I., McPherson, T.D., Hunter, J.C., Kirking, H.L., Christiansen, D., Joshi, K., Rubin, R., MoralesEstrada, S., Black, S.R., Pacilli, M., Fricchione, M.J., Chugh, R.K., Walblay, K.A., Ahmed, N.S., Stoecker, W.C., Hasan, N.F., Burdsall, D.P., Reese, H.E., Wallace, M., Wang, C., Moeller, D., Korpics, J., Novosad, S.A., Benowitz, I., Jacobs, M.W., Dasari, V.S., Patel, M.T., Kauerauf, J., Charles, E.M., Ezike, N.O., Chu, V., Midgley, C.M., Rolfes, M.A., Gerber, S.I., Lu, X., Lindstrom, S., Verani, J.R., \& Layden, J.E. (2020). First known person-to-person transmission of severe acute respiratory syndrome coronavirus 2 (SARS-CoV-2) in the USA. The Lancet, 395(10230), 1137-1144. doi:10.1016/S0140-6736(20)30607-3

Huang. C., Wang, Y., Li, X., Ren, L., Zhao, J., Hu, Y., Zhang, L., Fan, G., Xu, J., Gu, X., Cheng, Z., Yu, T., Xia, J., Wei, Y., Wu, W., Xie, X., Yin, W., Li, H., Liu, M., Xiao, Y., Gao, H., Guo, L., Xie, J., Wang, G., \& Cao, B. (2020). Clinical Features of Patients Infected With 2019 Novel Coronavirus in Wuhan, China. The Lancet, 395(10223), 497-506. doi:10.1016/s01406736(20)30183-5

Iyengar, K., Bahl, S., Vaishya, R., \& Vaish, A. (2020). Challenges and solutions in meeting up the urgent requirement of ventilators for COVID19 patients. Diabetes and Metabolic Syndrome, 14(4), 499-501. doi:10.1016/j.dsx.2020.04.048
Jayaweera, M., Perera, H., Gunawardanam, B., \& Manatunge, J. (2020). Transmission of COVID19 virus by droplets and aerosols: A critical review on the unresolved dichotomy. Environmental Research, 188, 109819. doi:10.1016/j.envres.2020.109819

Liu, D.X., Liang, J.Q., \& Fung, T.S. (2020). Human Coronavirus-229E, -OC43, -NL63, and -HKU1 Ding X. Liu, Jia. Reference Module in Life Sciences, B978-0-12-809633-8.21501-X. doi:10.1016/B978-0-12-809633-8.21501-X

Mackenzie, J.S. \& Smith, D.W. (2020). COVID-19: a novel zoonotic disease caused by a coronavirus from China: what we know and what we don't. Microbiology Australia, [Epub ahead of print], MA20013. doi:10.1071/MA20013

Möhlenkamp, S. \& Thiele, H. (2020). Ventilation of COVID-19 patients in intensive care units. Herz, [Epub ahead of print], 1-3. doi:10.1007/s00059-020-04923-1

Nicola, M., O'Neill, N., Sohrabi, C., Khan, M., Agha, M., \& Agha, R. (2020). Evidence based management guideline for the COVID-19 pandemic - Review article. International Journal of Surgery, 77, 206-216. doi:10.1016/j.ijsu.2020.04.001

Pal, M., Berhanu, G., Desalegn, C., Kandi, V. (2020). Severe Acute Respiratory Syndrome Coronavirus-2 (SARS-CoV-2): An Update. Cureus, 12(3), e7423. doi:10.7759/cureus.7423

Perencevich, E.N., Diekema, D.J., \& Edmond, M.B. (2020). Moving Personal Protective Equipment into the Community: Face Shields and Containment of COVID-19. JAMA, 323(22), 2252-2253. doi:10.1001/jama.2020.7477

Raoult, D., Zumla, A., Locatelli, F., Ippolito, G., \& Kroemer, G. (2020). Coronavirus infections: Epidemiological, clinical and immunological features and hypotheses. Cell Stress, [Epub ahead of print]. doi:10.15698/cst2020.04.216

Savi, C.D., Hughes, D.L., \& Kvaerno, L. (2020). Quest for a COVID-19 Cure by Repurposing SmallMolecule Drugs: Mechanism of Action, Clinical Development, Synthesis at Scale, and Outlook for Supply. Organic Process Research and Development, [Epub ahead of print]. doi:10.1021/acs.oprd.0c00233 
Singhal, T. (2020). A Review of Coronavirus Disease-2019 (COVID-19). Indian Journal of Pediatrics, 87(4), 281-286. doi:10.1007/s12098-020-03263-6

Tan, W., Zhao, X., Ma, X., Wang, W., Niu, P., Xu, W., Gao, G.F., \& Wu, G. (2020). A Novel Coronavirus Genome Identified in a Cluster of Pneumonia Cases - Wuhan, China 2019-2020. China CDC Weekly, 2(4), 61-62. doi:10.46234/ccdcw2020.017

Wang, L., Wang, Y., Ye, D., \& Liu, Q. (2020). Review of the 2019 novel coronavirus (SARS-CoV-2) based on current evidence. International Journal of Antimicrobial Agents, [Epub ahead of print], 105948. doi:10.1016/j.jantimicag.2020.105948

Weiss, S.R. \& Navas-Martin, S. (2005). Coronavirus Pathogenesis and the Emerging Pathogen Severe Acute Respiratory Syndrome Coronavirus. Microbiology and Molecular Biology Reviews, 69(4), 635-664. doi:10.1128/MMBR.69.4.635-664.2005

Wilson, N.M., Norton, A., Young, F.P., \& Collins, D.W. (2020). Airborne transmission of severe acute respiratory syndrome coronavirus-2 to healthcare workers: a narrative review. Anaesthesia, [Epub ahead of print]. doi:10.1111/anae.15093

Woo, P.C.Y., Huang, Y., Lau, S.K.P., \& Yuen, K.Y. (2010). Coronavirus Genomics and Bioinformatics Analysis. Viruses, 2(8), 1804-1820. doi:10.3390/v2081803

World Health Organization. (2020a). QEA on coronaviruses (COVID-19): What are the symptoms of COVID-19? https://www.who.int/emergencies/diseases /novel-coronavirus-2019/question-andanswers-hub/q-a-detail/q-acoronaviruses\#: :text=symptoms

World Health Organization. (2020b). Coronavirus disease (COVID-19) advice for the public. https://www.who.int/emergencies/diseases /novel-coronavirus-2019/advice-for-public

Wu, R., Wang, L., Kuo, H.C.D., Shannar, A., Peter, R., Chou, P.J., Li, S., Hudlikar, R., Liu, X., Liu, Z., Poiani, G.J., Amorosa, L., Brunetti, L., \& Kong, A.N. (2020). An Update on Current Therapeutic Drugs Treating COVID-19. Current Pharmacology Reports, [Epub ahead of print], 1-15. doi:10.1007/s40495-020-00216-7
Yi, Y., Lagniton, P.N.P., Ye, S., Li, E., \& Xu, R.H. (2020). COVID-19: what has been learned and to be learned about the novel coronavirus disease. International Journal of Biological Sciences, 16(10), 1753-1766. doi:10.7150/ijbs.45134

Yin, Y. \& Wunderink, R.G. (2018). MERS, SARS and Other Coronaviruses as Causes of Pneumonia. Respirology, 23(2), 130-137. doi:10.1111/resp.13196 